\title{
CORRECTION
}

Furukawa $\mathrm{H}$, et al.

A case of septum formation of the common hepatic duct combined with an anomalous hepatic duct of the caudate lobe Gastroenterol Jpn 1992;27(1):102-107.

\section{Page 103}

Figure 1 has appeared upside down. The Figure 1 is properly printed below.

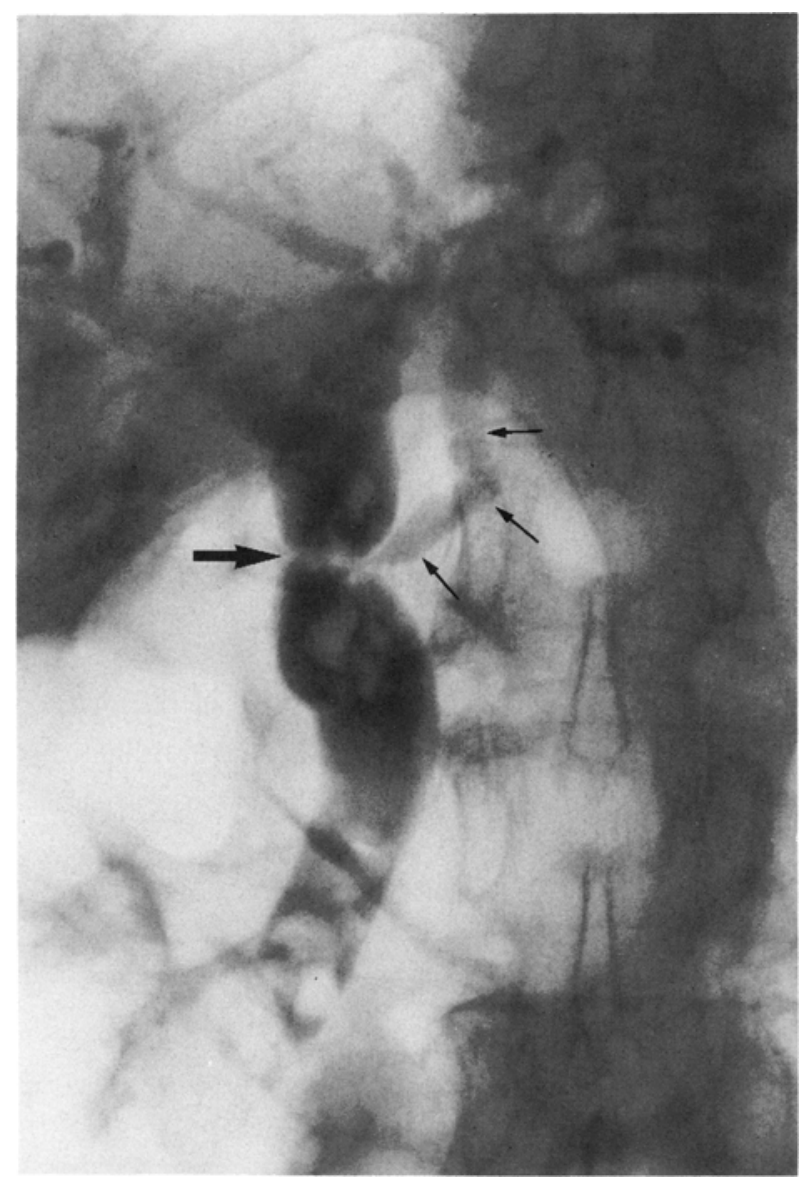

Fig. 1 ERC shows choledochal stones and septum formation (large arrow) of the common hepatic duct to where an anomalous hepatic duct (small arrow) drains from the caudate lobe of the liver. 